\title{
Regulation of mitochondrial iron homeostasis by sideroflexin 2
}

\author{
Ei Ei Mon ${ }^{1} \cdot$ Fan-Yan Wei $^{1,4} \cdot$ Raja Norazireen Raja Ahmad ${ }^{1} \cdot$ Takahiro Yamamoto $^{1}$ - Toshiro Moroishi ${ }^{2,3,4}$. \\ Kazuhito Tomizawa ${ }^{1,3,5}$
}

Received: 25 October 2018 / Accepted: 10 December 2018 / Published online: 20 December 2018 (c) The Author(s) 2018

\begin{abstract}
Mitochondrial iron is indispensable for heme biosynthesis and iron-sulfur cluster assembly. Several mitochondrial transmembrane proteins have been implicated to function in the biosynthesis of heme and iron-sulfur clusters by transporting reaction intermediates. However, several mitochondrial proteins related to iron metabolism remain uncharacterized. Here, we show that human sideroflexin 2 (SFXN2), a member of the SFXN protein family, is involved in mitochondrial iron metabolism. SFXN2 is an evolutionarily conserved protein that localized to mitochondria via its transmembrane domain. SFXN2-knockout (KO) cells had an increased mitochondrial iron content, which was associated with decreases in the heme content and heme-dependent enzyme activities. By contrast, the activities of iron-sulfur cluster-dependent enzymes were unchanged in SFXN2-KO cells. Moreover, abnormal iron metabolism impaired mitochondrial respiration in SFXN2-KO cells and accelerated iron-mediated death of these cells. Our findings demonstrate that SFXN2 functions in mitochondrial iron metabolism by regulating heme biosynthesis.
\end{abstract}

Keywords Mitochondria $\cdot$ Iron $\cdot$ Respiration $\cdot$ OXPHOS $\cdot$ Heme

Electronic supplementary material The online version of this article (https://doi.org/10.1007/s12576-018-0652-2) contains supplementary material, which is available to authorized users.

Fan-Yan Wei

fywei@kumamoto-u.ac.jp

$\triangle$ Kazuhito Tomizawa

tomikt@kumamoto-u.ac.jp

1 Department of Molecular Physiology, Faculty of Life Sciences, Kumamoto University, Honjo 1-1-1, Chuo-Ku, Kumamoto 860-8556, Japan

2 Department of Molecular Enzymology, Faculty of Life Sciences, Kumamoto University, Kumamoto 860-8556, Japan

3 Center for Metabolic Regulation of Healthy Aging, Faculty of Life Sciences, Kumamoto University, Kumamoto 860-8556, Japan

4 Precursory Research for Embryonic Science and Technology (PRESTO), Japan Science and Technology Agency (JST), Kawaguchi 332-0012, Japan

5 Neutron Therapy Research Center, Okayama University, Okayama 700-8558, Japan

\section{Introduction}

Iron is an essential element that is involved in the regulation of diverse biological processes, including oxygen transport, metabolism, respiration, and the cell cycle [1-3]. A large portion of cellular iron is bound to heme, which is an essential component of hemoglobin and respiratory complexes [4]. In addition, iron is utilized for the biogenesis of iron-sulfur clusters, which are indispensable for the activities of several enzymes related to RNA modification and redox signaling [5-7]. Given the essential role of iron, its deficiency often induces anemia in women and children, which can lead to severe complications such as inflammation and heart failure [8-11]. On the other hand, excess iron exerts cytotoxic effects because ferrous iron is highly active and can generate reactive oxygen species [12]. Indeed, iron overload has been linked to several diseases, such as osteoporosis, cancer, and neurological disorders [13-17].

Extracellular iron is mainly transported to the cytosol via transferrin receptor-mediated endocytosis [18]. Subsequently, a portion of cytosolic iron is transported to mitochondria for the biosynthesis of heme and iron-sulfur clusters, which are exported back to the cytosol [18]. Biosynthesis of heme and iron-sulfur clusters involves 
multiple chemical reactions and requires the transport of reaction intermediates across the inner and outer mitochondrial membranes [18]. Perturbation of this trafficking not only impairs the biosynthesis of heme and iron-sulfur clusters but also causes mitochondrial iron overload, leading to iron-mediated cytotoxicity.

Several mitochondrial transmembrane proteins have been implicated in the transport of iron-sulfur clusters and heme. For example, ATP-binding cassette subfamily $\mathrm{B}$ member 7 (ABCB7) is a transmembrane protein located in the inner mitochondrial membrane and is proposed to export iron-sulfur clusters $[19,20]$. The absence of ABCB7 impairs the maturation of cytosolic iron-sulfur proteins and induces iron accumulation in mitochondria [20]. Importantly, patients carrying a defective $A B C B 7$ gene exhibit sideroblastic anemia, which is characterized by abnormal iron accumulation in mitochondria [21-23]. Other mitochondrial transmembrane proteins, including SLC25A38 [24], ATP-binding cassette subfamily B member 6 (ABCB6) [25], and ATP-binding cassette subfamily $\mathrm{B}$ member 10 (ABCB10) [26], have been implicated in the transport of reaction intermediates in heme biosynthesis. Deficiencies in these transporters result in the accumulation of intermediates and impair heme synthesis, leading to abnormal iron accumulation in mitochondria [27, 28]. However, the molecular mechanism underlying the trafficking of heme and its intermediates are unclear.

The sideroflexin 1 (Sfxnl) gene was originally identified in a study of flexed-tail (f/f) mice, which exhibit hematological phenotypes [28, 29]. In 2001, Fleming et al. found a single base insertion in exon 2 of Sfxnl, which is predicted to induce a frameshift and thus lead to lossof-function of this gene in $f / f$ mice [29]. Importantly, $f / f$ mice exhibit excess iron accumulation in mitochondria of erythrocytes [30,31], suggesting that Sfxn1 is involved in mitochondrial iron homeostasis. Sfxn1 is a mitochondrial protein belonging to the SFXN protein family in mammals [29]. The mammalian Sfxn family consists of five members: Sfxn1-Sfxn5. The expression patterns of Sfxn genes differ in mouse tissues. Specifically, Sfxnl and $S f x n 2$ are highly expressed in the liver and kidney, $S f x n 3$ is ubiquitously expressed except in the lung, and Sfxn 4 and Sfxn5 are lowly expressed in major tissues. Although the molecular functions of Sfxn proteins are unclear, recent studies demonstrated that these proteins are involved in physiological functions and disease. For example, Sfxn3 has been implicated in the differentiation of pancreatic islets in mice and the regulation of synaptic morphology at neuromuscular junctions in Drosophila [32, 33]. Pathogenic mutations of the SFXN4 gene have been identified in mitochondrial disease patients with macrocytic anemia [34]. Furthermore, SFXN4 is a susceptibility gene for common familial colorectal cancer [35].
The present study investigated the physiological role of human SFXN2, an uncharacterized SFXN family protein. We report that SFXN2 is an outer mitochondrial membrane protein that functions in mitochondrial iron homeostasis by regulating heme biosynthesis.

\section{Results}

\section{SFXN2 is an evolutionarily conserved transmembrane protein}

To examine the conservation of SFXN2 across species, we compared its sequences between eight representative eukaryotic species: Homo sapiens, Mus musculus, Bos taurus, Xenopus tropicalis, Drosophila melanogaster, Caenorhabditis elegans, Danio rerio, and Saccharomyces cerevisiae. Phylogenetic analysis demonstrated that SFXN2 is evolutionarily conversed from yeast to humans (Fig. 1a). SFXN2 proteins in vertebrates and invertebrates exhibit 70-91\% and $44-56 \%$ similarity with human SFXN2, respectively. A previous in silico study demonstrated that fungal sideroflexin-1 (FSF1) is a fungal homolog of human SFXN proteins [36]. Indeed, human SFXN2 shows $31.8 \%$ similarity to yeast FSF1. Alignments of human SFXN2 with its homologs showed that conserved amino acids are evenly distributed from the $\mathrm{N}$-terminus to the $\mathrm{C}$-terminus. All these SFXN2 proteins contain five putative transmembrane domains and a long N-terminal region consisting of $\sim 100$ amino acids (Fig. 1b). The C-terminus of these SFXN2 proteins is relatively short ( 40 amino acids), and the final eight amino acids are almost identical across the eight species.

\section{SFXN2 is a mitochondrial protein}

We conjugated human SFXN2 to the $\mathrm{C}$-terminus or $\mathrm{N}$-terminus of mCherry and examined its localization in HeLa cells to verify whether it is a mitochondrial protein. Both mCherry-SFXN2 and SFXN2-mCherry colocalized with the mitochondria-specific fluorescent dye MitoTracker (Fig. 2a, b). The majority of mCherry-SFXN2 and SFXN2mCherry colocalized with endogenous Tomm20, an outer mitochondrial membrane protein (Fig. 2c, d). Notably, some mitochondria were surrounded by mCherry-SFXN2 or SFXN2-mCherry, while the interior of mitochondria lacked mCherry fluorescent signals (Fig. 2c, d). This observation led us to speculate that SFXN2-mCherry and mCherry-SFXN2 localizes to the outer mitochondrial membrane. We purified mitochondria from HEK293 cells expressing SFXN2-mCherry and treated them with trypsin in the absence of detergent. Trypsin rapidly digested mitofusin1, which is an outer mitochondrial membrane protein, 
Fig. 1 Phylogenetic analysis of SFXN2 protein. a Phylogenetic analysis was performed using the UniProt website. The cladogram shows the evolutionary distances between SFXN2 proteins from representative species. Numbers on the right show the similarity of each SFXN2 protein to human SFXN2. b Amino acid sequences of SFXN2 proteins were aligned using ClustalW on the UniProt website. Completely conserved residues are shaded in gray and labeled with asterisks. Residues with high and moderate homology are indicated by colons and periods, respectively. Transmembrane (TM) segments are indicated by lines
A

Similarity to

human SFXN2 (\%)

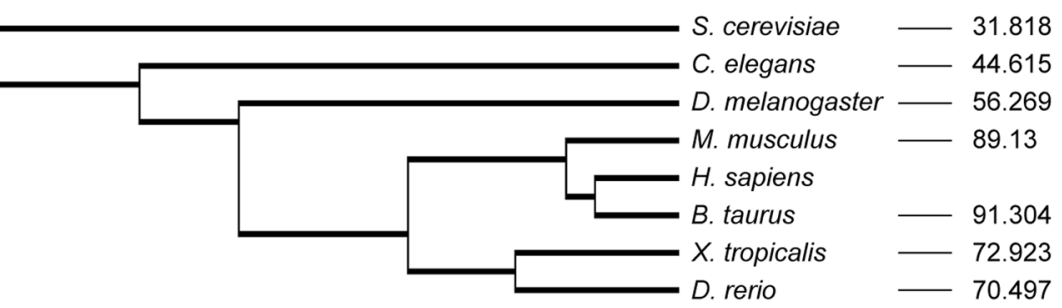

B

H. sapiens 1 ---MEADLSGFNIDAPRWDQRTFLGRVKHFLNITDPRTVFVSERELDWAKVMVEKSRMGV

M. musculus 1 ---MEGDLSGFNIDAPRWDQCTFLGRVKHFFNITDPRTVFASEQELDWAKAVVEKSRMGL

B. taurus 1 ---MEADLSDFNIDAPRWDOCTFLGRVKHFFNITDPRTVLVPERELDWAKVMVEOSRMGT

X. tropicalis ---MSOVSTLIDVDKPLFDLSTFAGRFOYFAWMTDPRTVVVSSDRLIEAKAMVERYRKGD MTTMEMESSKFNIDAPRWDOSTFVGRLKHFFNITDPRTALVSEQELDSAKLLVDSCRAGS MTTMEMESSKFNIDAPRWDQSTFVGRLKHFFNITDPRTALVSEQELDSAKLLVDSCRAGS ------MAFDPDOPRYDOSTFYGRLRHFAGMTDPLIAFSSTTELITASELMOKCREKK --MASSVPGPIDLPESRYDLSTYWGRIRHCAE ISDPTMLLTTEKDLAHAREI ISAYRHGE

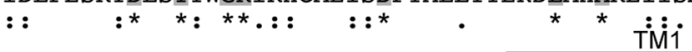

C. elegans

S. cerevisiae

H. sapiens 58 VPPGTQVEQLLYAKKLYDSAFHPDTGEKMNVIGRMSFQLPGGMIITGFMLQFYRTMPAVI M. musculus 58 VPPGTOMEOLLYAKKLYDSAFHPDTGEKMNVIGRMSFOVPGGMLITGFMLOFYRTMPAVI B. taurus 58 VPPGTOVEOLFYAKKLYDSAFHPDTGHKMNVIGRMSFOVPGGMIITGFMLOFYRTMPAVI D. melanogaster 58 QSPPLKPEEVHYNMKLYNSAFHPDTGELQNFCGRMSFQVPGGMLITGGMLAFYRTVPAVV melanogaster
$x$. tropicalis
61

D. rerio 57 VPPGTTEEQLHYAKKLYDSAFHPDTGDRMNLIGRMSFQVPGGMAITGFMLQFYRTVPAVV

C. elegans 53 -PVPATLEELHRSORLCOSAFHPDTGELONFAGRMCFNVWGGTMLCGAMMIWYKSTPAVI

S. cerevisiae 59 LKE--TTPEFWRAKKQLDSTVHPDTGKTVLLPFRMSSNVLSNLVVTVGMLTPGLGTAGTV

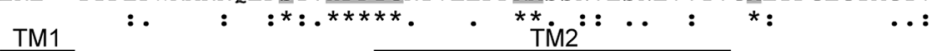
FWQWVNQSFNALVNYTNRNAASPTSVRQMALSYFTATTTAVATAVGM-NMLTKK------FWOWVNOSFNALVNYTNRNAASPTSVROMALSYFTATTTAVATAVGM-NMWTKR-----TWWVNOS FALVNYTNRNA SPTSVROMAVSYITATTTAVATAVGM-NMLTKR---FWQWVNQSFNALVNYTNRNAASPTSVRQMAVSYITATTTAVATAVGM-NMLTKR------LWQFINQSFNAVVNYTNRNANSPTSVTQLGVAYVSATTSALVAAIGCKNYWSKK-----FWQWVNQSFNALVNYTNRNAASPITLTQIGVAYLTATSTALATAVGL-NLYTKK------FWQWVNQSFNALVNYTNRNAASPITPKQIGVAYVTATSTALATAVGL-NLYTKK-----FWOWANOSFNALVNYTNRNAKSTLTTKDLVVSYSTAVSGALAMAIGLKTYFAKK------Q FWQWANOSLNVAVNSANANKSHPMSTSQLLTNYAAAVTASCGVALGLNNLVPRLKNISPH $: * *: * * * * . * *: * * \quad: \quad:: *: * .:: x^{*}: *$ : $\frac{\text { TM3 } 3}{*}{ }^{*} \cdot *$ TM4

S. cerevisiae 117 APPLVGRWVPFAAVAAANCVNI PMMROOELIOGICVKDRNONELGHSORAAAVGIAOVVI APPLVGRWVPFAAVAAANCVNIPMMROQEIIQGICVKDRNHNEIGHSRRAAAIGITQVVI ATPLFQRFVPFAAVAAANFVNI PLMRQNEI INGIEVKNDDGVVVGQSRLAAIKGIGEVVV APPLIARWVPFAAVAAANCVN I PMMROQEL INGIAVTDENDNKLGHSRKAAIKGISOVVI APPLVARWVPFAAVAAANCVNI PMMROQEILHGIAVTDEDGNKLGHSRKAAVKGITQVVI SSPLAORLVPLGAVAVANAINI PMMRONELKEGMTVTDADGNNVGVSRLAAAKAISLVVI SKLILGRLVPFAAVVSAGIVNVFLMRGNEIRKGISVFDSNGDEVGKSKKAAFMAVGETAI

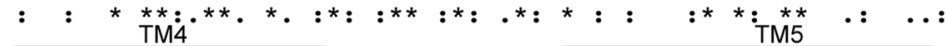
SRITMSAPGMILLPVIMERLEKLHFM-OKVKVLHAPLOVMLSGCFLIFMVPVACGLFPOK SRITMAAPGMILLPVIMERLERLHLM-KKVKVMHAPLOVLLCGCFLLFMVPVACGLFPOF SRITMAAPGMILLPVIMERLERLHLM-KKVKVMHAPLQVLLCGCFLLFMVPVACGLFPQE SRITMAAPGMILLPVLMERLEKLRFV-QRVRVLHAPLQVLLSGCFLIFMVPVACGLFPQQ SRIAMAAPGMILLPILMERL EAFPFM-KKIRFLHAPLOVMLAGGFLLFMVPVACSLFPOR SRVTMAAPGMI ILPI IMORLEKHRFM-OKITFLHGPLOVMMVGVFLIFMVPAACSLFPOR SRNI IVAPCMILTPVIMEGLNKVASFRKHINKLNIPTQLALTFVIYGAMIPVGCALFPQQ SRNIIVAPCMILTPVIMEGLNKVASFRKHINKLNIPTQLALTFVIYGAMIPVGCALFPQQ
SRVINATPTMVIPPLILVRLQRGVLKGKSLGV-QTLANLGLISVTMFSALPFALGIFPQR

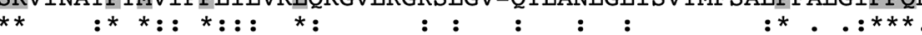

$\begin{array}{lll}\text { H. sapiens } 290 & \text { CELPVSY---LEPKLQDTIKAK-YGELEPYVYFNKGL } \\ \text { M. musculus } & 290 & \text { CELSVSY---LEPELRDTIKAK-YGEOVLFVYFNKGL }\end{array}$

$\begin{array}{ccc}\text { M. musculus } 290 & \text { CELSVSY---LEPELRDTIKAK-YGEQVLFVYFNKGL } \\ \text { B. taurus } & 290 & \text { CELPVSY---LEPELQDTIKAK-YREPVPHVYFNKGL }\end{array}$

D. melanogaster 291 CSLDTSIMRTFEPELYEDLEKKTOGKVPKRVYFNKGL

X. tropicalis 293 CSMPVSS---LEPELRESIVKO-YGEOIRYVYFNKGL

D. rerio 289 CSMAVSK---LEPELRESIISO-YGEOISHVYFNKGL

C. elegans 287 NSVKLSTLKRWEPEAFEKLKNI----KGDRVYFNKGL

$\begin{aligned} \text { S. cerevisiae } 296 \text { QAIHLNK---LEPELHGKKD--KDGKPIEKVYFNRGI } & \text { : } \\ * * * *: * & \text { : }\end{aligned}$ and SFXN2-mCherry (Fig. 2e, f). By contrast, Timm50, which is an inner mitochondrial membrane protein, was resistant to trypsin digestion (Fig. 2e, f). These results suggest that SFXN2-mCherry is targeted to the outer mitochondrial membrane.

\section{Mitochondrial targeting signal in SFXN2}

Targeting of proteins to mitochondria is very complicated, and the targeting signal might be embedded in various regions of the protein. A mitochondrial targeting signal was previously proposed to be located in the N-terminal region 
A

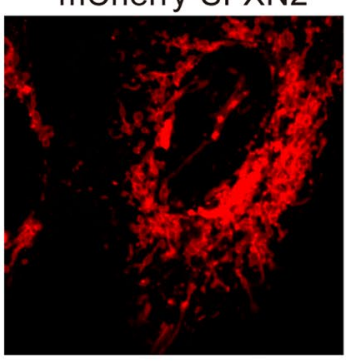

B

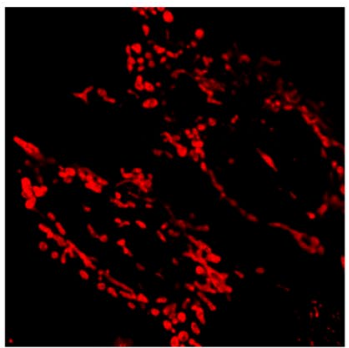

SFXN2-mCherry
MitoTracker
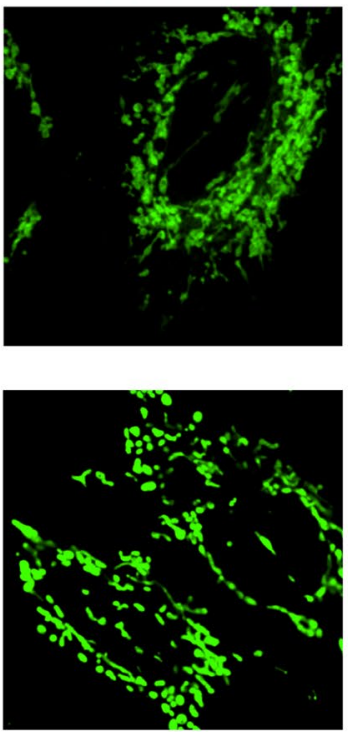

MitoTracker
Merge
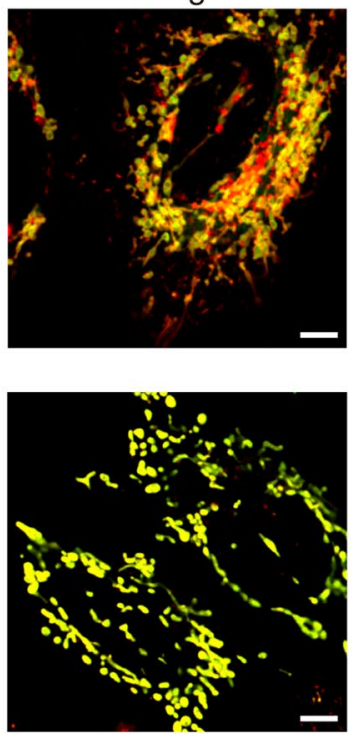

Merge
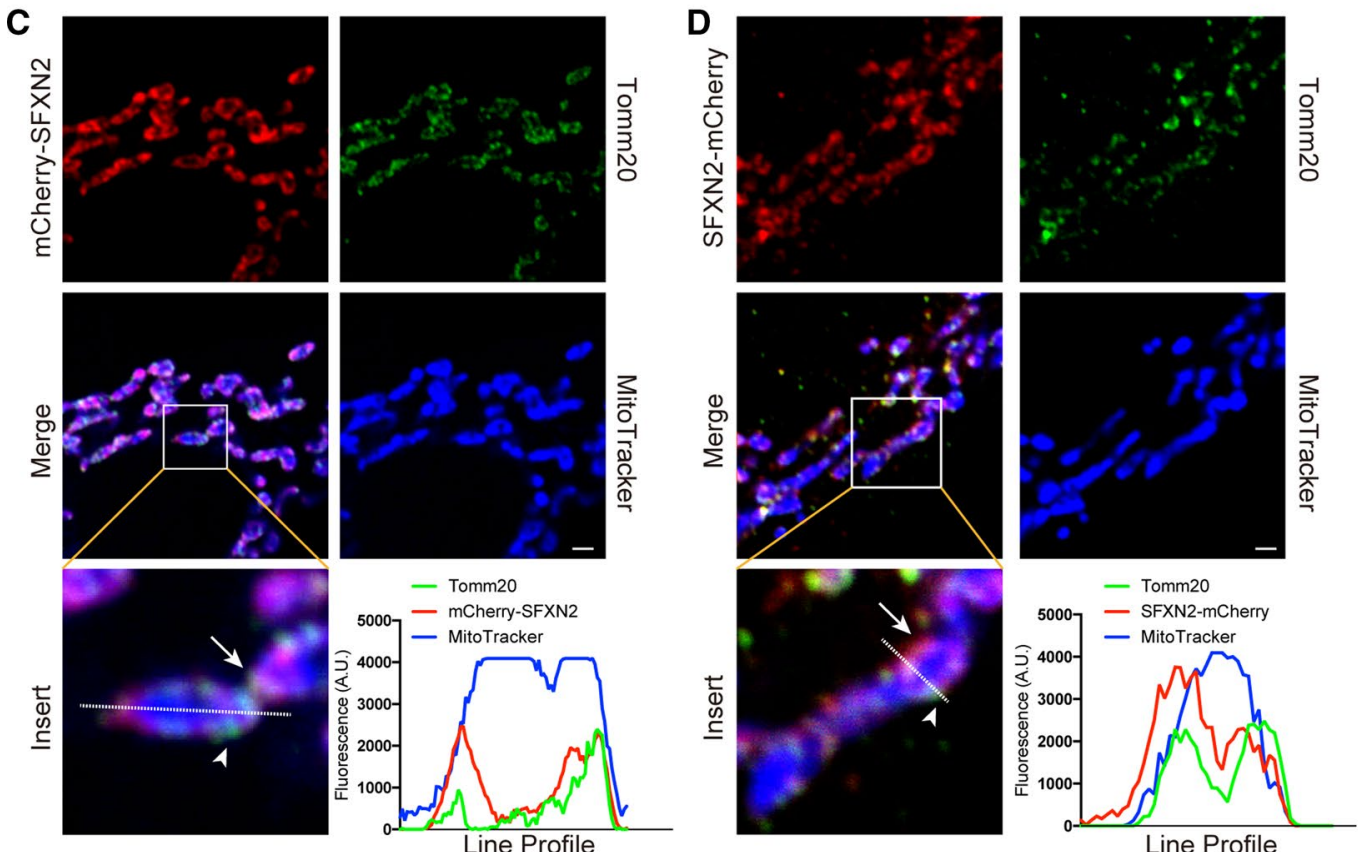

E
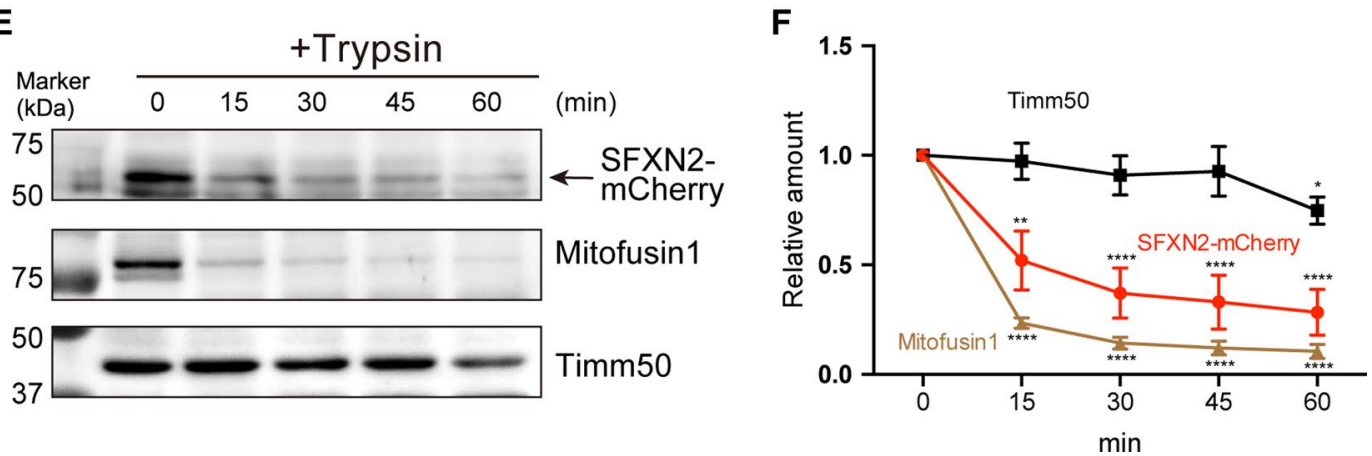
४Fig. 2 Mitochondrial localization of SFXN2. mCherry-SFXN2 (a) and SFXN2-mCherry (b) colocalized with MitoTracker. Bar $=5 \mu \mathrm{m}$. mCherry-SFXN2 (c) and SFXN2-mCherry (d) colocalized with MitoTracker and endogenous Tomm20. Arrows indicate mCherrySFXN2 or SFXN2-mCherry, while arrowheads indicate Tomm20. The fluorescence intensities along the dashed lines are shown as line profile graphs. Bars $=1 \mu \mathrm{m}$. e Mitochondria were isolated from HEK293 cells transfected with SFXN2-mCherry and then digested with trypsin. SFXN2, Mitofusin1, and Timm50 were detected by Western blotting. The arrow indicates bands corresponding to SFXN2-mCherry. f Quantification of SFXN2-mCherry, Mitofusin1, and Timm50. $n=3-4$ each. $* p<0.05, * * p<0.01$, **** $p<0.0001$ by a two-way ANOVA

of SFXN proteins [36]; therefore, we conjugated the N-terminal region of SFXN2 to mCherry and examined its localization. In contrast with full-length SFXN2 shown in Fig. 2, the chimeric SFXN2 $2_{\mathrm{Nterm}}$-mCherry protein failed to localize to mitochondria (Fig. 3a). Likewise, mCherry conjugated to the C-terminal tail of SFXN2 failed to localize to mitochondria (Fig. 3b). These data demonstrate that the mitochondrial targeting signal is not located in the N-terminus or C-terminus of SFXN2; therefore, we speculated that it is present in the transmembrane domains. We truncated SFXN2 at the end of the second transmembrane domain and conjugated it to mCherry. This chimeric protein (SFXN2 $\left.{ }_{\mathrm{N}-\mathrm{TM} 2}-\mathrm{mCherry}\right)$ colocalized with MitoTracker (Fig. 3c). Furthermore, the combination of the first transmembrane domain (TM1) and the N-terminus of SFXN2 (SFXN2 ${ }_{\mathrm{N}-\mathrm{TM} 1}$-mCherry) was sufficient for targeting to mitochondria (Fig. 3d). Mitochondrial targeting of SFXN2 ${ }_{\mathrm{N}-\mathrm{TM} 1}$-mCherry was less efficient than that of SFXN2 ${ }_{\mathrm{N}-\mathrm{TM}}$-mCherry (Pearson's colocalization efficient $=0.728$ for SFXN2 ${ }_{\mathrm{N}-\mathrm{TM} 2}-\mathrm{mCherry}$ and 0.627 for SFXN2 ${ }_{\mathrm{N}-\mathrm{TM} 1}$-mCherry, Fig. $3 \mathrm{e}$ ).

\section{Iron accumulates in mitochondria of SFXN2-knockout (KO) cells}

The mitochondrial localization of SFXN2 prompted us to examine its role in mitochondrial iron homeostasis. Sfxn2 was highly expressed in mouse kidney and liver (Fig. S1A). Notably, SFXN2 was also expressed in human embryonic kidney 293 (HEK293) cells, and was the third most highly expressed isoform among the five $S F X N$ isoforms (Fig. S1B). We then generated SFXN2-knockout (KO) HEK293 cells using CRISPR-Cas9-mediated genome editing [37]. We designed a guide RNA (gRNA) that targets exon 4 of SFXN2. After colony selection and genomic PCR, one clone showed a potential deletion near to exon 4 (Fig. 4a). Subsequent DNA sequencing revealed that a part of exon 4 and the entire exon 5 of SFXN2 was deleted (Fig. 4b). To examine whether overall transcription of SFXN2 was impaired by this targeted deletion, we performed quantitative PCR using primers complementary to exon 1 of $S F X N 2$. The mRNA level of SFXN2 in SFXN2-KO cells was $10 \%$ of that in control cells stably expressing $\operatorname{Cas} 9$ (Fig. 4c). Notably, the levels of other $S F X N$ family members did not differ between SFXN2-KO and control cells (Fig. 4c).

To examine the mitochondrial iron content, we purified mitochondria and extracted total iron using nitric acid. The extract was subjected to inductively coupled plasma-mass spectrometry (ICP-MS) for iron quantification. The iron content was significantly higher in mitochondria purified from SFXN2-KO cells than in mitochondria purified from control cells (Fig. 4d). ICP-MS cannot distinguish between ferric and ferrous iron when measuring the iron content; therefore, we treated control and SFXN2-KO cells with a fluorescent iron probe that localizes to mitochondria and specifically labels ferrous iron [38]. Confocal microscopy revealed that the fluorescence intensity of this iron probe was significantly higher in SFXN2-KO cells than in control cells (Fig. 4e, f). Importantly, expression of SFXN2-mCherry significantly reduced the mitochondrial ferrous iron level in SFXN2-KO cells, while expression of Mito-DsRed, a fluorescent mitochondrial protein, did not (Fig. 4g-i). These results clearly demonstrate that SFXN2 is required for maintenance of mitochondrial iron homeostasis.

\section{The heme level is decreased in SFXN2-KO cells}

The majority of mitochondrial iron is utilized to synthesize heme and iron-sulfur clusters [18]. Dysfunctional heme biosynthesis and iron-sulfur cluster assembly prevent efficient iron usage, leading to iron accumulation and defective respiration in mitochondria. The labile heme content is generally proportional to the total heme content [39]. Therefore, we measured the labile heme content in SFXN2-KO cells by monitoring peroxidase activity. The labile heme content was significantly lower in SFXN2-KO cells than in control cells (Fig. 5a). We also measured the total heme content by mass spectrometry. Similar to the labile heme content, the total heme content was significantly lower in SFXN2-KO cells than in control cells (Fig. 5b, c).

Heme and iron-sulfur clusters are essential for the activities of mitochondrial respiratory complexes. Complex I contains iron-sulfur clusters, complex IV contains heme, and complexes II and III contain both heme and iron-sulfur clusters [40]. The activities of complexes II-III and IV were significantly lower in SFXN2-KO cells than in control cells (Fig. 5d, e). On the other hand, the activity of complex I did not differ between SFXN2-KO and control cells (Fig. 5f). Collectively, the defective activities of complexes II-IV were associated with a decrease in the maximum oxygen consumption rate (OCR) in SFXN2-KO cells (Fig. $5 \mathrm{~g}$ ). In addition to respiratory complex activities, we examined the level of the 2-methylthio modification of mitochondrial tRNA by mass spectrometry. This modification is mediated by $\mathrm{Cdk} 5$ regulatory subunit-associated 
Fig. 3 Mitochondrial targeting signal in SFXN2. The $\mathrm{N}$-terminus (a) or C-terminus (b) of SFXN2 was conjugated to mCherry and then expressed in HeLa cells. SFXN2 $2_{\text {Nterm }}$-mCherry and mCherry-SFXN2 $2_{\text {Cterm }}$ were diffusely distributed. c SFXN2 was truncated at the end of the second transmembrane domain and conjugated to mCherry. The fusion protein colocalized with MitoTracker. d A SFXN2 fragment containing the $\mathrm{N}$-terminus and the first transmembrane domain was conjugated to mCherry. The fusion protein colocalized with mitochondria. Bars $=5 \mu \mathrm{m}$. e Pearson's colocalization coefficient was calculated to examine the extent of colocalization between the fluorescence of MitoTracker and the fluorescence of each chimeric protein (a-d). $n=5$ for SFXN $2{ }_{\text {Nterm }}$-mCherry (Nterm) and mCherrySFXN2 2 Cterm $($ Cterm), $n=16$ for SFXN2 $2_{\text {N-TM2 }}$-mCherry (TM2), and $n=14$ for SFXN2 $2_{\mathrm{N}-\mathrm{TM} 1}$-mCherry (TM1). $* p<0.05, * * * * p<0.0001$ by a one-way ANOVA
A
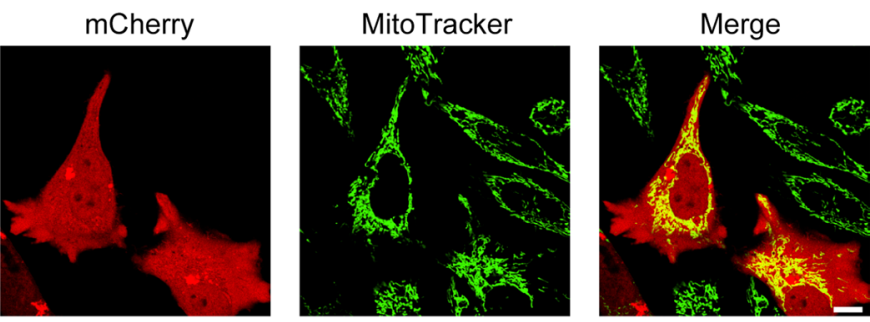

B

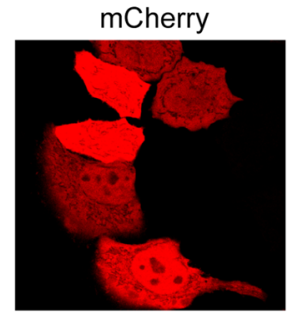

MitoTracker
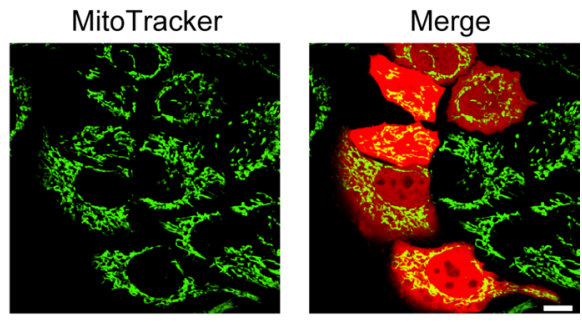

C
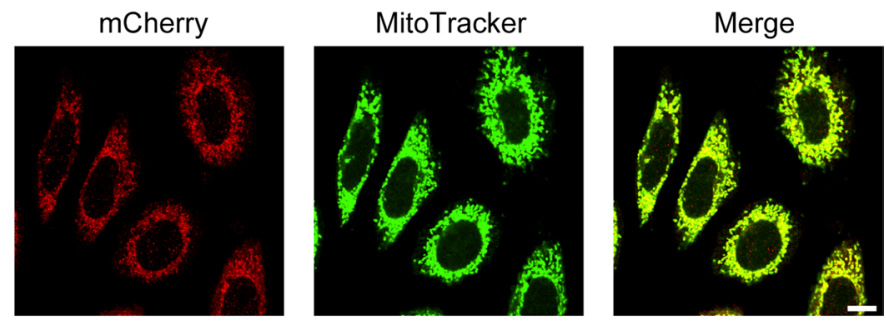

D

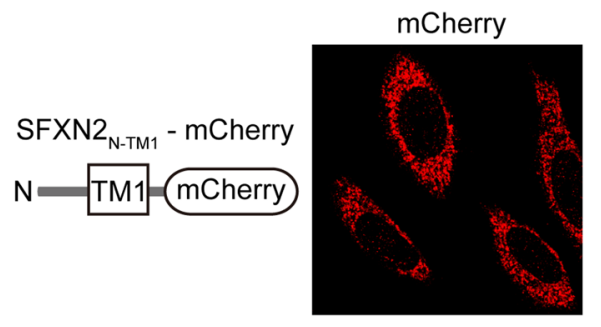

MitoTracker
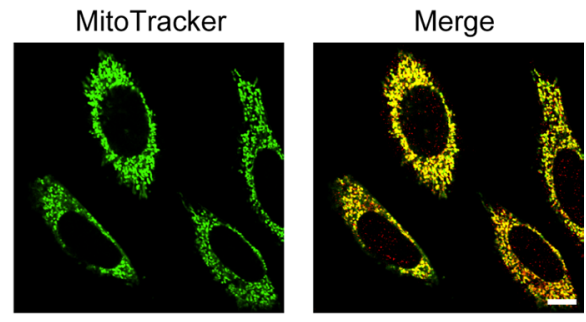

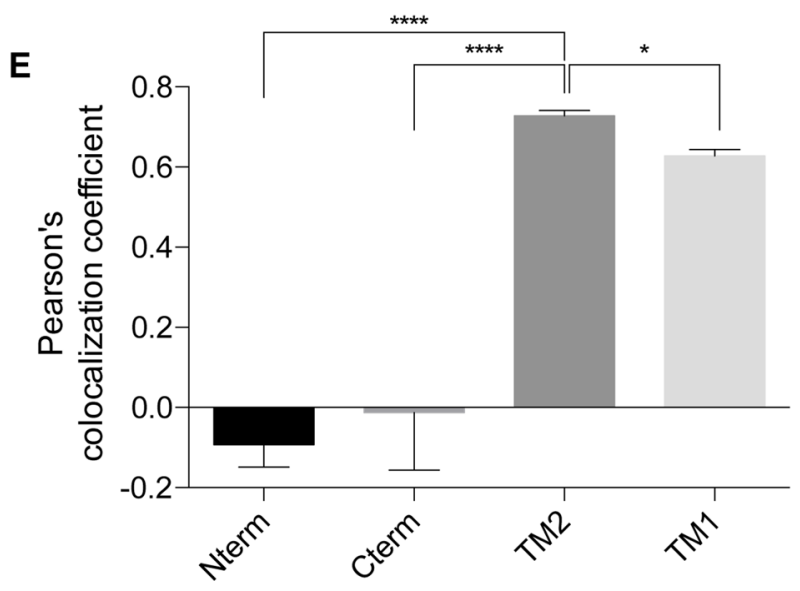

protein 1 (CDK5RAP1), a mitochondrial iron-sulfur cluster-dependent tRNA-modifying enzyme [41, 42]. Similar to complex I activity, the level of the 2-methylthio modification of tRNA did not differ between SFXN2-KO and control cells (Fig. 5h). Thus, SFXN2 might be involved in heme biosynthesis, but not in iron-sulfur cluster assembly.

We further examined expression of genes related to iron transport and heme biosynthesis in SFXN2-KO cells. 
Fig. 4 Iron accumulates in mitochondria of SFXN2-KO cells. a Genotyping of SFXN2-KO and control cells. b Alignment of DNA sequences of control and SFXN2-KO cells. Green letters show DNA regions corresponding to exon 4 and exon 5 of SFXN2. Grey box shows the deleted region in SFXN2KO cells. $\mathbf{c}$ The mRNA level of $S F X N 2$ was significantly lower in SFXN2-KO cells than in control cells. Expression of $S F X N 1$, $S F X N 3, S F X N 4$, and SFXN5 did not differ between $S F X N 2-\mathrm{KO}$ and control cells. $n=3$ each. $* * * p<0.001$. d The mitochondrial iron content was measured using ICP-MS. This content was significantly higher in SFXN2$\mathrm{KO}$ cells than in control cells. $n=3$ each. $* * p<0.01$. e The mitochondrial iron contents of control and SFXN2-KO cells were investigated using MitoFerroGreen. Bar $=10 \mu \mathrm{m}$. f The fluorescence intensity of MitoFerroGreen was significantly higher in SFXN2-KO cells than in control cells. $n=100$ control cells and 200 SFXN2-KO cells. $* * * * p<0.0001 . \mathbf{g}, \mathbf{h}$ Control and SFXN2-KO cells were transfected with Mito-DsRed (g) or SFXN2-mCherry (h), and iron was stained with MitoFerroGreen. i Quantification of the fluorescence intensity of Mito-FerroGreen in mock transfected cells and in cells transfected with Mito-DsRed and SFXN2-mCherry. $n=10-12$. $* * * * p<0.0001$. Expression of SFXN2-mCherry, but not of Mito-DsRed, suppressed iron accumulation in SFXN2-KO cells
A
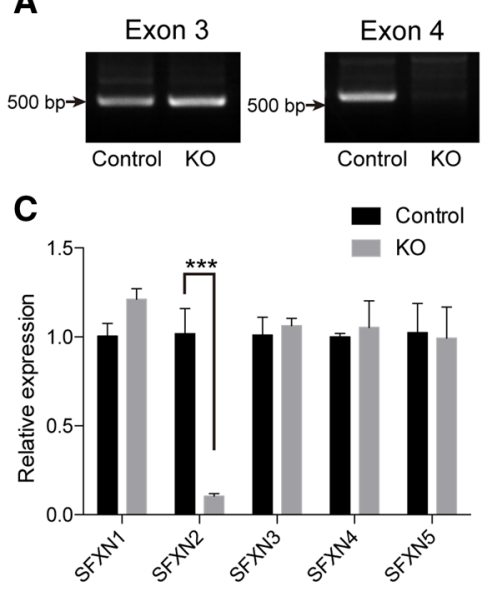

E
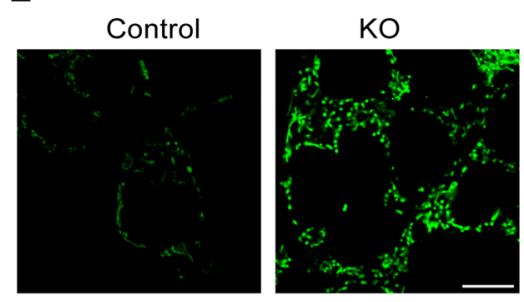

G Mito-
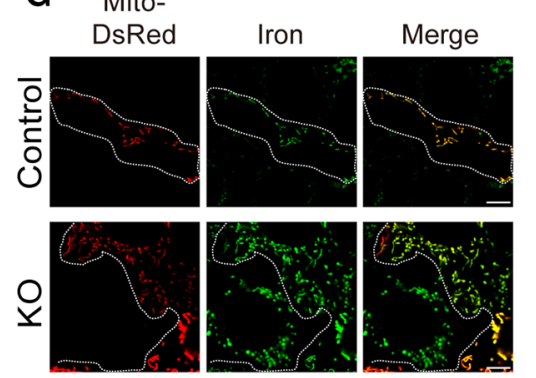

B

Control Exon4 4......CAACCACTGCTGTGGCC.......ntron......EXon5......GGCATG...Intron

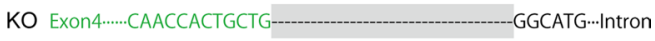

D

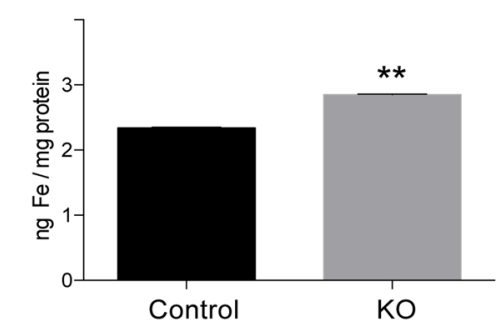

$\mathbf{F}$

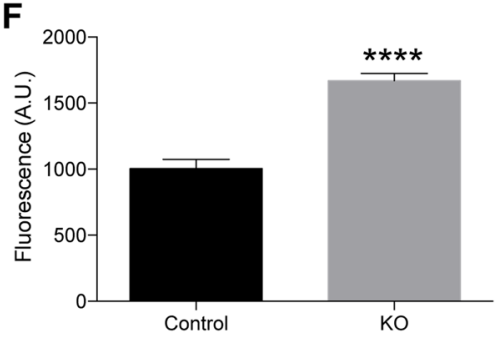

$\mathrm{H}_{\text {SFXN2- }}$

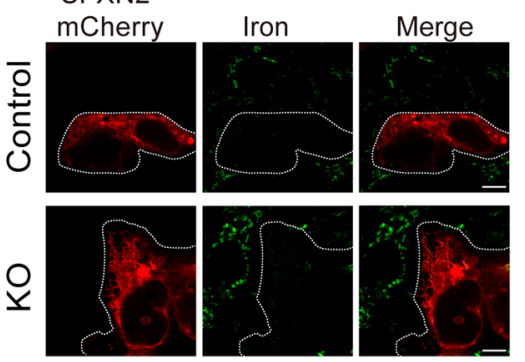

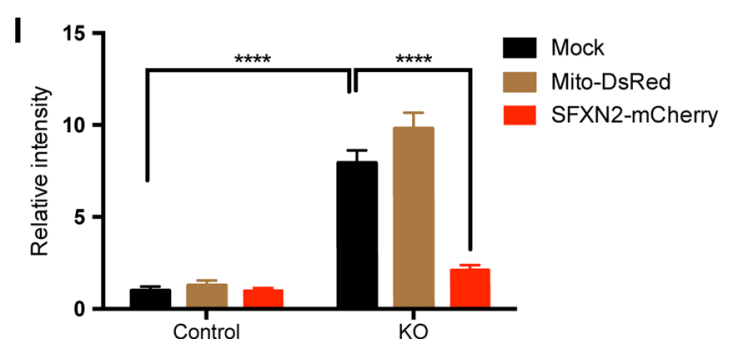

Expression of Mitoferrin1 (MFRN1), Mitoferrin2 (MFRN2), and Frataxin $(F X N)$, which are related to iron import and iron-sulfur cluster assembly [43, 44], did not differ between $S F X N 2-\mathrm{KO}$ and control cells (Fig. 6a-c). ABCB6, ABCB10, and $A L A S 2$ are related to heme biosynthesis [25, 26, 45]. Expression of these genes did not differ between SFXN2$\mathrm{KO}$ and control cells (Fig. 6d-f). In addition, we examined the protein level of FXN by Western blotting. Consistent with its mRNA expression, the protein level of FXN did not differ between SFXN2-KO and control cells (Fig. 6g).
These results demonstrate that abnormal iron homeostasis in SFXN2-KO cells is not due to dysfunction of other proteins related to iron import and iron-sulfur cluster assembly.

\section{SFXN2-KO cells are sensitive to iron-mediated cytotoxicity}

Given the decrease in mitochondrial respiration and the accumulation of iron in mitochondria, we speculated that SFXN2-KO cells might be sensitive to iron-induced 

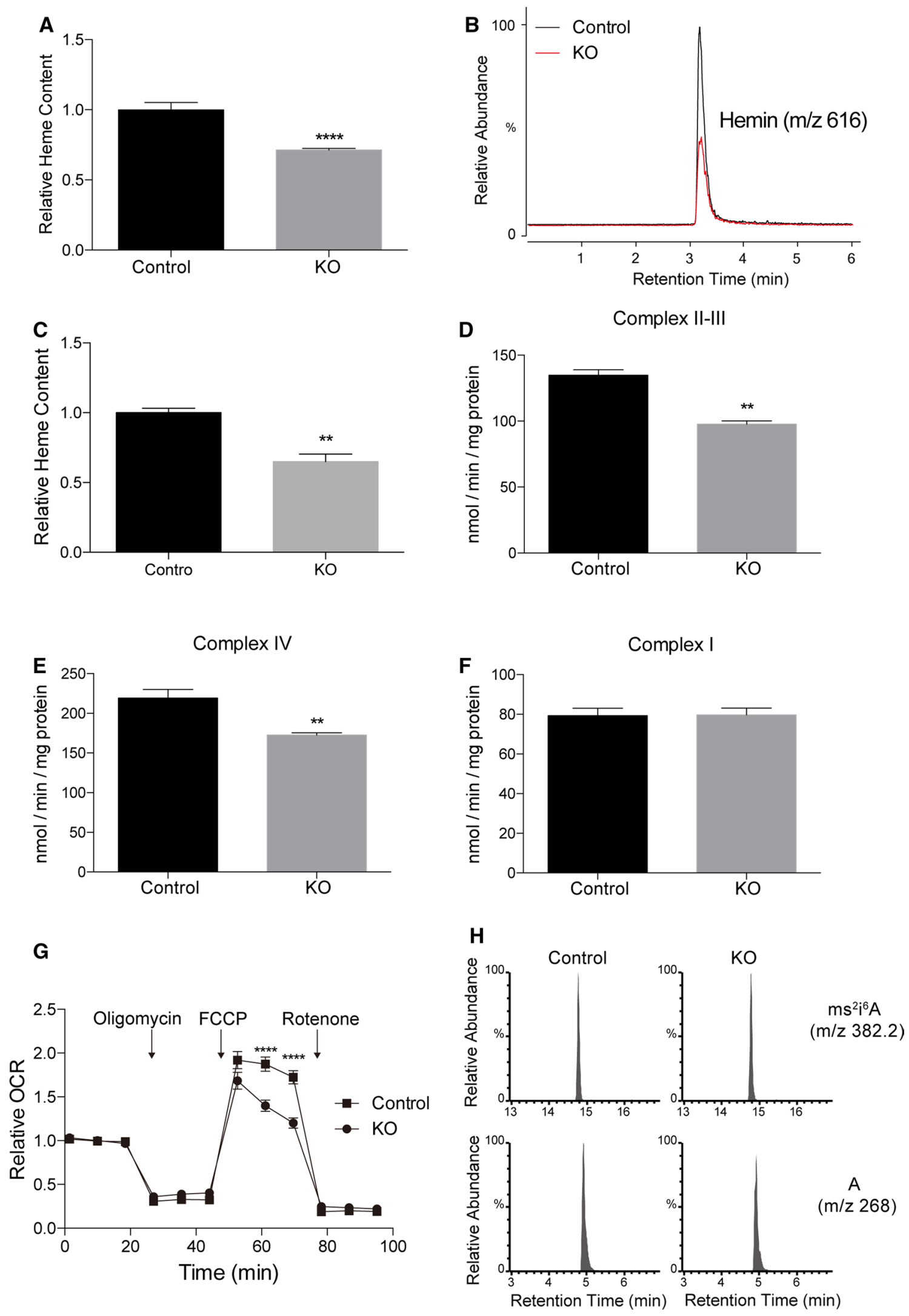
4Fig. 5 The heme level and heme-dependent enzyme activities are decreased in SFXN2-KO cells. a The relative labile heme level was lower in SFXN2-KO cells than in control cells. b Total heme (hemin) was isolated from control and SFXN2-KO cells. Representative mass spectra are shown. c The total hemin content was significantly lower in $S F X N 2-\mathrm{KO}$ cells than in control cells. $n=3$. ${ }^{* *} p<0.01$. d, e Activities of complexes II-III and IV were significantly lower in SFXN2KO cells than in control cells. $n=3$ each. $* * p<0.01$. f Complex I activity did not differ between SFXN2-KO and control cells. $n=3$ each. $\mathrm{g}$ The relative OCR was measured in control and $S F X N 2-\mathrm{KO}$ cells. The maximum OCR was significantly decreased in $S F X N 2-\mathrm{KO}$ cells after application of $10 \mu \mathrm{M}$ FCCP. $n=4$ each. $* * * * p<0.0001$. h Representative mass spectra of the $\mathrm{ms}^{2} \mathrm{i}^{6} \mathrm{~A}$ (2-methylthio- $N^{6}$-isopentenyladenosine) modification in control and $S F X N 2-\mathrm{KO}$ cells. Unmodified adenosine (A) was examined as a loading control. The $\mathrm{ms}^{2} \mathrm{i}^{6} \mathrm{~A}$ level did not differ between control and SFXN2-KO cells

cytotoxicity. SFXN2-KO cells grew significantly slower than control cells (Fig. 7a). Upon exposure to excess iron, the growth rate of SFXN2-KO cells was suppressed more than that of control cells (Fig. 7b). Furthermore, we treated cells with erastin in an attempt to induce cytotoxic ferroptosis, a form of iron-mediated cell death [46]. Erastin treatment significantly decreased the viability of $S F X N 2-\mathrm{KO}$ cells (Fig. 7c, d). In addition, we assessed cell death by performing trypan blue staining and monitoring release of lactate dehydrogenase (LDH) into the culture medium (Fig. 7e, f). Erastin treatment increased the number of SFXN2-KO cells stained with trypan blue (Fig. 7e) and significantly augmented release of LDH into the culture medium by SFXN2KO cells (Fig. 7f). Taken together, these results demonstrate that SFXN2-KO cells are sensitive to iron toxicity.

\section{Discussion}

The present study demonstrated that human SFXN2 is a mitochondrial protein that regulates mitochondrial iron homeostasis. SFXN2-KO cells exhibited abnormal mitochondrial iron accumulation, which was associated with a decrease in mitochondrial respiration. In addition, SFXN2$\mathrm{KO}$ cells displayed a growth defect upon iron overload and were susceptible to erastin-induced death. These results demonstrate that SFXN2 is important for maintenance of mitochondrial iron homeostasis. Iron homeostasis is also perturbed in Sfxn1- and SFXN4-deficient cells [29, 34]; therefore, it is conceivable that SFXN family proteins are evolutionarily conserved to regulate mitochondrial iron homeostasis.

What is the role of SFXN2 in mitochondrial iron homeostasis? Iron is imported from the cytosol into mitochondria for biosynthesis of heme and assembly of iron-sulfur clusters, which are subsequently exported back to the cytosol. Defects in genes related to heme biosynthesis or iron-sulfur cluster assembly lead to aberrant iron accumulation in mitochondria [18]. The high mitochondrial iron content in SFXN2-KO cells was associated with decreases in the heme content and heme-dependent enzyme activities. By contrast, the activities of iron-sulfur cluster-dependent enzymes were unchanged in SFXN2-KO cells. These results suggest that SFXN2 is involved in heme biosynthesis, but not in iron-sulfur cluster assembly.

Heme biosynthesis involves multiple enzymatic reactions that occur sequentially in the cytosol and mitochondria. Accordingly, the intermediates of these chemical reactions must be imported into and exported from mitochondria. Despite the complexity, only a few transmembrane proteins have been reported to mediate this transport. For example, the inner mitochondrial membrane protein SLC25A38 transports glycine, which is required for the first step of heme synthesis [24], while ABCB6 and ABCB10 are involved in import of protoporphyrin into mitochondria [28, 47]. However, these transporters cannot explain the entire heme transport system. Interestingly, a very recent study revealed that SFXN1 is a mitochondrial serine transporter [48]. Serine hydroxymethyltransferase 2 metabolizes serine into glycine in mitochondria; therefore, loss of SFXN1 reduces de novo glycine synthesis in mitochondria, leading to defects in one-carbon metabolism including purine synthesis. Given the essential role of glycine in biosynthesis of heme, it is conceivable that defective heme synthesis in SFXN2-KO cells is due to impaired serine transport and de novo glycine synthesis. A further study is required to elucidate the role of SFXN2 in serine transport and its relevance to heme biosynthesis.

SFXN2 (and SFXN1) is predominantly expressed in the liver and kidney, and is lowly expressed in other tissues. This differential expression pattern might be due to differences in the requirement for hemoglobin and heme synthesis. The fetal liver is the major organ involved in erythropoiesis during the late phase of embryogenesis [49]. In adults, the liver and cortex of the kidney have a high heme-synthesizing capacity, which sustains the activity of cytochrome P450 to detoxify endogenous and exogenous substances [50]. The high demand for hemoglobin and heme in the liver and kidney might explain why SFXN2 is highly expressed in these organs. On the other hand, despite its low abundance, SFXN2 is also required for synthesis of heme and purine nucleotides to sustain cellular activity in other tissues. SFXN3-SFXN5 may compensate for low expression of SFXN2 in these tissues. A further study using knockout mice is required to elucidate the physiological roles of SFXN2 and other SFXN family members.

Proteins are targeted to mitochondria by specific signals. The targeting signals are usually located in the N-terminal, internal, and C-terminal regions of mitochondrial proteins with a single transmembrane segment [51]. Some outer mitochondrial membrane proteins, such as peripheral 
Fig. 6 Expression of genes related to mitochondrial metabolism is unchanged in SFXN2-KO cells. Expression of MFRN1 (a) and MFRN2 (b), which are related to mitochondrial iron import, did not differ between control and SFXN2-KO cells. c Expression of $F X N$, which is related to iron-sulfur cluster assembly, did not differ between control and SFXN2-KO cells. Expression of $A B C B 6$ (d), $A B C B 10$ (e), and $A L A S 2$ (f), which are related to heme biosynthesis, did not differ between control and SFXN2-KO cells. $n=3$ each. g Protein levels of FXN and Vdac in mitochondria isolated from control and SFXN2-KO cells were examined by Western blotting. Vdac was used as a loading control
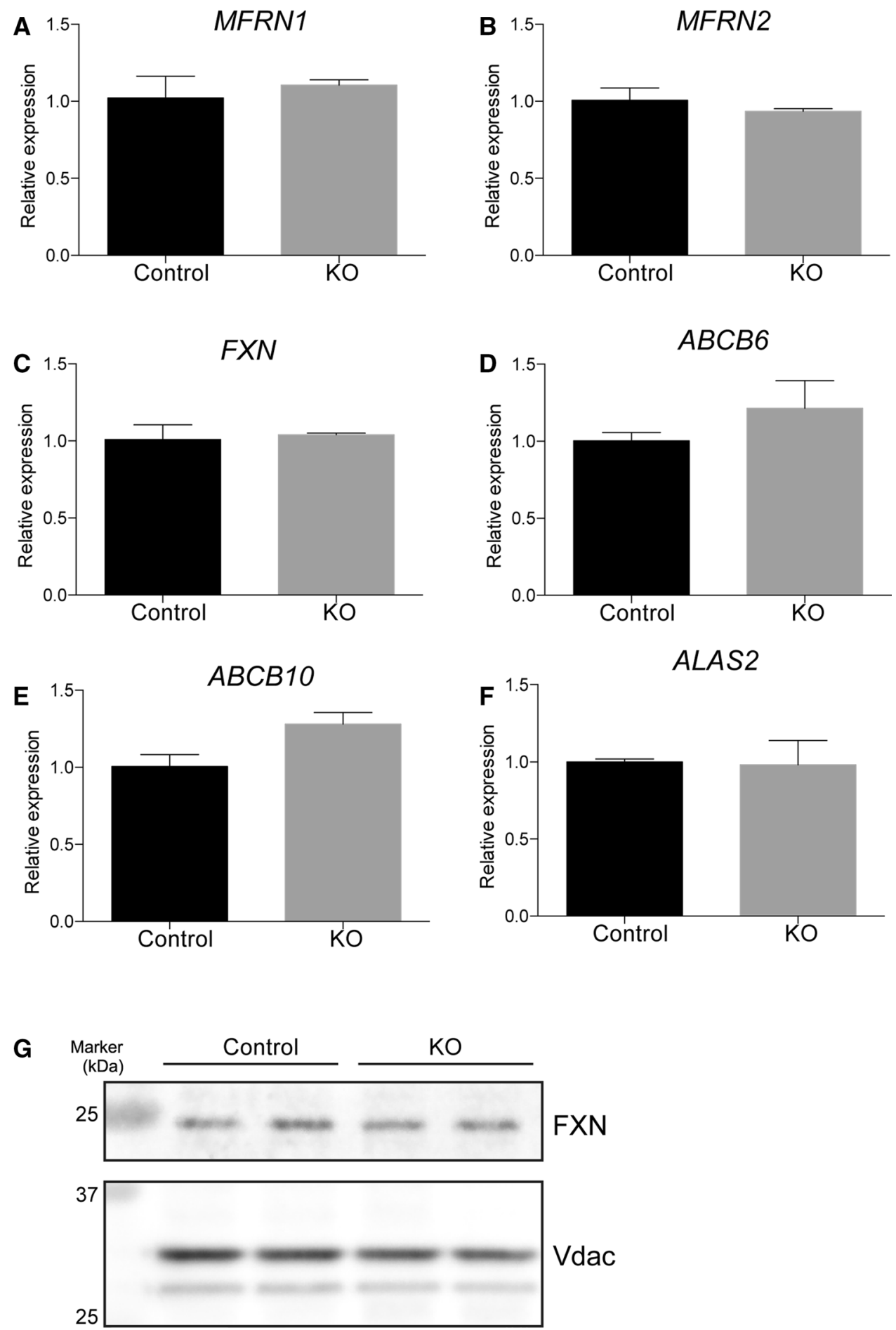

benzodiazepine receptor, contain several transmembrane segments, and the location of the targeting signal is unclear [52]. A previous in silico study predicted that the targeting signal of SFXN2 is located in its N-terminal region [36]. However, neither the N-terminus nor the C-terminus was sufficient for targeting of SFXN2 to mitochondria in the present study. Instead, the transmembrane domains of SFXN2 functioned as a mitochondrial targeting signal and guided SFXN2 to the mitochondria. In contrast to SFXN2, SFXN3, and SFXN4 are targeted to the inner mitochondrial membrane $[33,34]$. Sequence homology is $54 \%$ between SFXN2 and SFXN3, but only $20 \%$ between SFXN2 and SFXN4 (Fig. S2). SFXN3 contains one fewer putative transmembrane domains, which are potentially important for mitochondrial targeting (Fig. 3), than 

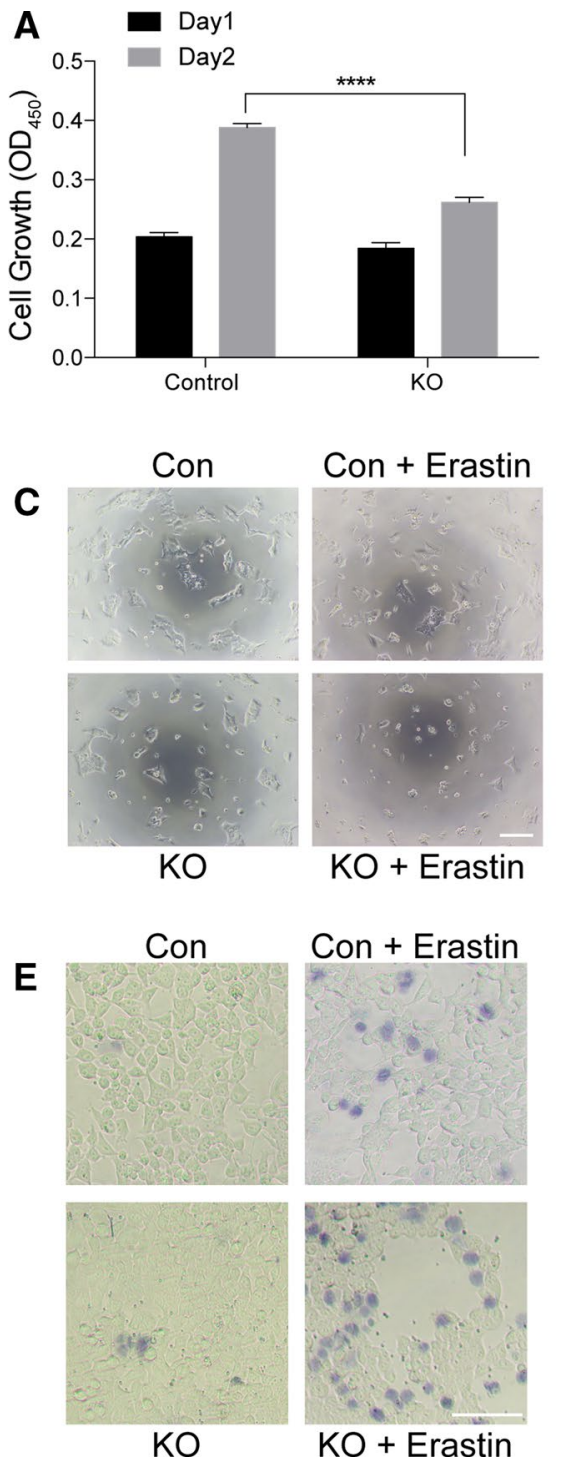

Fig. 7 SFXN2-KO cells display increased sensitivity to iron. a Control and $S F X N 2-\mathrm{KO}$ cells were seeded in 96-well plates at a density of 5000 cells/well. $S F X N 2-\mathrm{KO}$ cells grew significantly slower than control cells. $n=7-8$. $* * * * p<0.0001$. b Control and SFXN2-KO cells were treated with the indicated concentrations of ferric ammonium citrate (FAC) for $24 \mathrm{~h}$. Growth of SFXN2-KO cells was slowed more than that of control cells in the presence of FAC. $n=7-8$. $* p<0.05, * * p<0.01, * * * * p<0.0001$. c Control and SFXN2-KO cells were treated with $10 \mu \mathrm{M}$ erastin for $24 \mathrm{~h}$ and then observed under a microscope. The density of SFXN2-KO cells was markedly reduced

SFXN2 (Fig. S2). A further study is needed to elucidate the localizations of endogenous SFXN proteins.

All SFXN family genes are expressed in HEK293 cells, but only SFXN2 was deleted in the present study. Given the moderate decrease in the heme level, the remaining SFXN proteins likely compensated for the loss of SFXN2 function. Consistently, the hematological phenotypes are mild
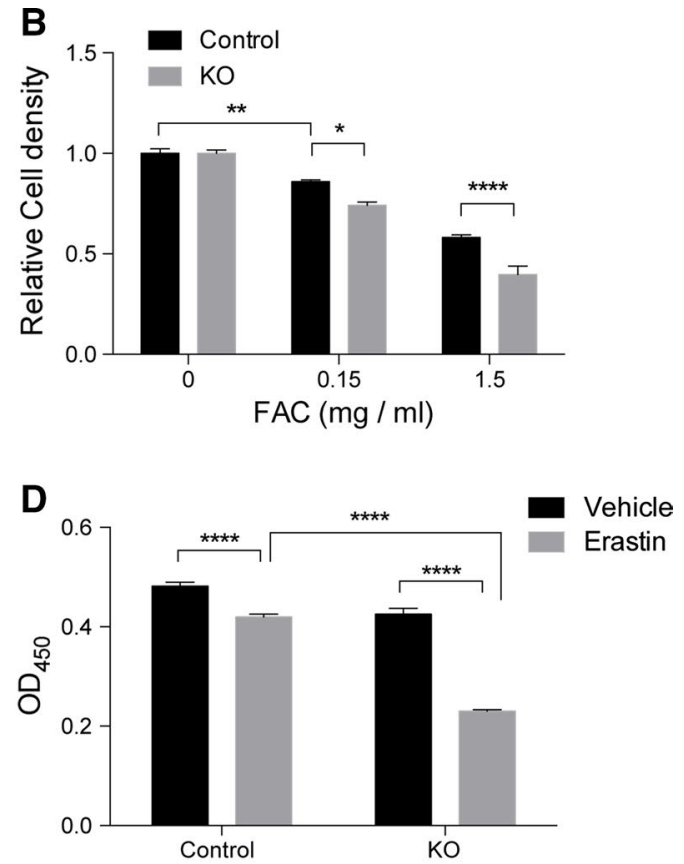

$\mathbf{F}$

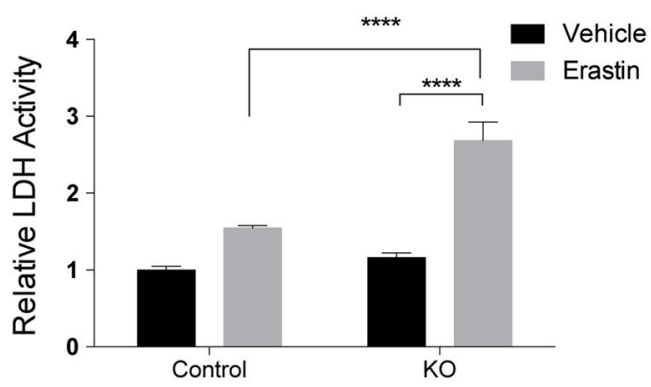

upon erastin treatment. Bar $=200 \mu \mathrm{m}$. d Cell viability was measured using the WST-8 reagent. Erastin treatment decreased the viability of SFXN2-KO cells significantly more than that of control cells. $n=7-8$. **** $p<0.0001$. e Control and SFXN2-KO cells were stained with trypan blue, which labels dead cells. Erastin treatment increased the number of SFXN2-KO cells that were labeled with trypan blue. Bar $=200 \mu \mathrm{m}$. f Cell death was assessed by measuring LDH activity in the culture medium. Erastin treatment significantly increased LDH activity in the culture medium of SFXN2-KO cells. ****p $<0.0001$

in Sfxn1-deficient $f / f$ mice [29], but severe in transgenic mice with defective heme biosynthesis [28, 45]. Simultaneous KO of multiple $S F X N$ genes is required to elucidate the functions of SFXN proteins.

In conclusion, SFXN2 is a mitochondrial membrane protein that regulates heme biosynthesis and contributes to mitochondrial iron homeostasis. 


\section{Materials and methods}

\section{Cell culture}

HEK293 and HeLa cells were cultured in Dulbecco's modified Eagle's medium (DMEM; Invitrogen) supplemented with $4500 \mathrm{mg} / \mathrm{l}$ glucose, 10\% fetal bovine serum (Corning), and $1 \times$ penicillin/streptomycin (Invitrogen) in an incubator containing $5 \% \mathrm{CO}_{2}$ at $37^{\circ} \mathrm{C}$.

\section{Plasmids and cDNA}

Human SFXN2 was amplified from human cDNA derived from HEK293 cells and subcloned into the pEF1a-mCherry$\mathrm{C} 1$ and pEF1a-mCherry-N1 vectors (Clontech). pDsRed2Mito was obtained from Clontech. For the generation of lentiviruses, lentiCRISPRv2 (\#52961), psPAX2 (\#12260), and pVSVg (\#8454) were purchased from Addgene.

\section{Generation of SFXN2-KO cells}

A gRNA targeting exon 4 of SFXN2 was selected using the CRISPR DESIGN web tool. DNA oligonucleotides were annealed and ligated into LentiCRISPRv2 that had been digested with BsmBI (New England BioLabs). Lentiviruses were generated in HEK293FT cells according to the manufacturer's instructions. Culture media containing viruses were filtered and stored at $-80{ }^{\circ} \mathrm{C}$ until use. HEK293 cells were infected with lentiviruses carrying the $\operatorname{Cas} 9$ gene and gRNA. Two days later, cells were seeded in 10-cm culture dishes at a density of 40 cells/dish in the presence of $2 \mu \mathrm{g} / \mathrm{ml}$ puromycin. Colonies were plated in 96-well dishes and subjected to genotyping.

\section{Immunocytochemistry}

HeLa and HEK293 cells were transfected with mCherrySFXN2 or SFXN2-mCherry using Lipofectamine 3000. Cells were stained with 100 nM MitoTracker Green FM (Invitrogen) or $100 \mathrm{nM}$ MitoTracker Deep Red FM (Invitrogen) for $30 \mathrm{~min}$. Thereafter, cells were fixed with $4 \%$ paraformaldehyde for $10 \mathrm{~min}$ at room temperature. Finally, cells were stained with an anti-Tomm20 antibody (Abcam, ab186734) and an antimCherry antibody (Abcam, ab125096), and then incubated with secondary antibodies conjugated with Alexa Fluor 488 and Alexa Fluor 546. Fluorescence was observed and analyzed using a confocal microscope (Olympus 3000) and FluoView software.

\section{Iron staining}

To label iron in mitochondria, cells were incubated with Mito-FerroGreen (Dojindo) in accordance with the manufacturer's instructions. Briefly, cells were washed thrice with serum-free DMEM. Mito-FerroGreen was freshly dissolved in dimethyl sulfoxide (Sigma) and added to cells at a final concentration of $5 \mu \mathrm{M}$. Cells were incubated with the reagent for $30 \mathrm{~min}$ at $37^{\circ} \mathrm{C}$ and then washed with phosphatebuffered saline (PBS). Fluorescence was observed using a confocal microscope.

\section{Isolation of mitochondria}

Cells were grown in 10-cm dishes until they reached $80 \%$ confluency, washed with PBS, and suspended in homogenization buffer (250 mM sucrose, $20 \mathrm{mM}$ Mops, $1 \mathrm{mM}$ EDTA, and a protease inhibitor cocktail (Sigma)). Thereafter, cells were homogenized with a Teflon homogenizer until 70-80\% of cells were lysed. The homogenate was centrifuged at $800 \mathrm{~g}$ for $10 \mathrm{~min}$ at $4{ }^{\circ} \mathrm{C}$, and the supernatant was centrifuged at $8000 \mathrm{~g}$ for $10 \mathrm{~min}$. The resulting pellet was used as the crude mitochondrial fraction. Frataxin was detected using an antibody (Abcam, ab175402).

\section{Trypsin digestion}

Isolated mitochondria were incubated with $25 \mu \mathrm{g} / \mathrm{ml}$ trypsin (Promega) on ice in homogenization buffer for the indicated durations. A trypsin inhibitor (Sigma) was added to stop the digestion. Mitochondria were washed with homogenization buffer and subjected to SDS-PAGE. Mitofusin 1 and Timm50 were selected as representative outer and inner mitochondrial membrane proteins, respectively. Mitofusin1, Timm50, and mCherry were detected using specific antibodies (ab104274, ab109436, and ab125096, respectively) purchased from Abcam.

\section{Measurement of mitochondrial respiratory complex activities}

The activities of mitochondrial complexes I, II-III, and IV were measured using previously described methods [41]. To measure complex I activity, $50 \mu \mathrm{g}$ of isolated mitochondria was mixed with $50 \mathrm{mM}$ potassium phosphate ( $\mathrm{pH} 7.4$ ), $2 \mathrm{mM}$ KCN, $75 \mu \mathrm{M}$ NADH (nicotinamide adenine dinucleotide reduced disodium salt), and $50 \mu \mathrm{M}$ coenzyme Q1. Absorbance at $340 \mathrm{~nm}$ was measured for $200 \mathrm{~s}$. To measure complex II-III activity, $50 \mu \mathrm{g}$ of isolated mitochondria was mixed with $50 \mathrm{mM}$ potassium phosphate ( $\mathrm{pH} 7.4)$, $20 \mathrm{mM}$ succinate, $0.5 \mathrm{mM}$ EDTA, $2 \mathrm{mM} \mathrm{KCN}$, and $30 \mu \mathrm{M}$ cytochrome C. Absorbance at $550 \mathrm{~nm}$ was measured for $200 \mathrm{~s}$. To measure complex IV activity, $50 \mu \mathrm{g}$ of isolated 
mitochondria was mixed with $10 \mathrm{mM}$ potassium phosphate (pH 7.4) and $10 \mu \mathrm{M}$ ferrocytochrome C. Absorbance at $550 \mathrm{~nm}$ was measured for $200 \mathrm{~s}$.

\section{Flux analysis}

Oxygen consumption was measured using a Seahorse XF Analyzer (Agilent), according to the manufacturer's instructions. Briefly, cells were seeded in a 24-well culture plate (Agilent) at a density of 50,000 cells/well. Oligomycin (Sigma), carbonyl cyanide 4-(trifluoromethoxy) phenylhydrazone (FCCP, Sigma), and rotenone (Sigma) were added sequentially and oxygen consumption was measured under each condition.

\section{Cell viability}

Control and SFXN2-KO cells were seeded in a 96-well plate at a density of 5000 cells/well. The following day, cells were treated with $10 \mu \mathrm{M}$ erastin (Sigma) and incubated for $24 \mathrm{~h}$. Cell viability was monitored using WST- 8 reagent (Dojindo) according to the manufacturer's instructions. Absorbance was measured at $405 \mathrm{~nm}$. To investigate cell death, control and SFXN2-KO cells were seeded in a 96-well plate at a density of 10,000 cells/well. The following day, cells were treated with $10 \mu \mathrm{M}$ erastin (Sigma) and incubated for $24 \mathrm{~h}$. Cell death was assessed by the LDH assay and trypan blue staining in the same well. The culture medium in each well was transferred to a fresh 96-well plate. The amount of LDH released into the culture medium was measured using a Cytotoxicity LDH Assay Kit-WST (Dojindo) according to the manufacturer's instructions. Cells were stained with trypan blue (Sigma) and examined under a microscope (Olympus) equipped with a CCD camera.

\section{Quantitative PCR}

Total RNA was extracted from cells using TRIzol (Invitrogen) according to the manufacturer's instructions. cDNA was generated using PrimeScript RT Master Mix (Takara), and then quantitative PCR was performed using TB Green Premix Ex Taq (Takara) and a Rotor-Gene Q system (Qiagen). The primer sequences are provided in Supplementary Table 1. The level of the target gene was normalized against that of $18 S$ rRNA for analyses in mouse tissues, while the levels of SFXN1-SFXN5 were normalized against that of Ubiquitin $C(U B C)$ for analyses in HEK293 cells. Relative expression was calculated using the $2^{\Delta \Delta C_{t}}$ method as described previously [53]. Expression levels of target genes were normalized against that of $18 \mathrm{~S}$ rRNA.

\section{Mass spectrometry}

The total mitochondrial iron content was measured using ICP-MS (Agilent 7900). Mitochondria were suspended in $2 \%$ nitric acid and heated at $80{ }^{\circ} \mathrm{C}$ for $15 \mathrm{~min}$ to extract iron. Denatured proteins were pelleted by centrifugation at $10,000 \mathrm{~g}$ for $15 \mathrm{~min}$, and the supernatant was subjected to ICP-MS analysis according to the manufacturer's instructions.

The level of the 2-methylthio- $N^{6}$-isopentenyladenosine modification of mitochondrial tRNA was measured using liquid chromatography-mass spectrometry (Shimadzu LCMS-8050) as previously described [42]. Briefly, total RNA was purified from control and SFXN2-KO cells. Five micrograms of total RNA was digested with nuclease P1 (Fujifilm-Wako). Nucleosides were fractionated using an Inertsil ODS-3 column and analyzed in multiple reaction monitoring mode.

\section{Measurement of labile heme}

After reaching $80 \%$ confluency, cells were washed with PBS, lysed in Tris-buffered saline containing $1 \%$ Triton X-100, sonicated, and centrifuged at $10,000 \mathrm{~g}$ for $10 \mathrm{~min}$. The heme content was measured using a Hemin Assay kit (Abcam, ab65332), which utilizes peroxidase activity to measure the level of heme. Protein concentrations were measured using a Pierce BCA assay kit (Thermo Fisher Scientific). Peroxidase activity was normalized against the total protein concentration.

\section{Measurement of total heme}

The total heme (hemin) content was measured by mass spectrometry according to a previously described method [54]. Briefly, $2 \times 10^{7}$ cells were suspended in $1 \mathrm{ml}$ of PBS, and an aliquot of the cell suspension was transferred to a fresh tube for measurement of the total protein concentration. The cell suspension was mixed with $3 \mathrm{ml}$ of acetonitrile to extract heme from proteins. Next, $2 \mathrm{ml}$ of acetonitrile/ $\mathrm{HCl}(8: 2)$ was added to the sample, followed by $0.5 \mathrm{ml}$ of saturated $\mathrm{MgSO}_{4}$ and $0.05 \mathrm{~g}$ of $\mathrm{NaCl}$. After brief centrifugation at $2600 \mathrm{~g}$ for $5 \mathrm{~min}$, the upper organic phase, which contained free hemin, was analyzed by mass spectrometry (Agilent 6470). The peak corresponding to hemin was normalized against the protein concentration.

\section{Statistical analysis}

At least three independent replicates were performed in all experiments. All data were analyzed using GraphPad Prism 6 software. The unpaired Student's $t$ test was used to assess the significance of differences between two groups. 
A two-way ANOVA followed by Tukey's multiple comparison test was used to examine the significance of differences between more than two groups. A two-tailed $p$ value of 0.05 was considered significant. Data are presented as the mean \pm SEM.

Acknowledgements We thank Nobuko Maeda (Kumamoto University) and Megumi Nagayama (Kumamoto University School of Medicine, Core Laboratory for Medical Research and Education) for providing technical assistance.

Funding This work was supported by Grants-in-Aid for Scientific Research from the Ministry of Education, Culture, Sports, Sciences, and Technology of Japan [17905074 and 18959602 to KT, 18H02599 and $18 \mathrm{~K} 19521$ to FYW, and $18 \mathrm{~K} 19433$ and $18 \mathrm{H} 02438$ to TM], the Japan Agency for Medical Research and Development (AMED) [17935694 to KT], and the Takeda Science Foundation [to KT].

\section{Compliance with ethical standards}

Conflict of interest All of the authors declare that they have no conflicts of interest.

Ethical approval This article does not contain any studies with human participants or animals performed by any of the authors.

Open Access This article is distributed under the terms of the Creative Commons Attribution 4.0 International License (http://creativeco mmons.org/licenses/by/4.0/), which permits unrestricted use, distribution, and reproduction in any medium, provided you give appropriate credit to the original author(s) and the source, provide a link to the Creative Commons license, and indicate if changes were made.

\section{References}

1. Zhang C (2014) Essential functions of iron-requiring proteins in DNA replication, repair and cell cycle control. Protein Cell 5:750-760. https://doi.org/10.1007/s13238-014-0083-7

2. Muckenthaler MU, Rivella S, Hentze MW, Galy B (2017) A red carpet for iron metabolism. Cell 168:344-361. https://doi. org/10.1016/j.cell.2016.12.034

3. Lv H, Shang P (2018) The significance, trafficking and determination of labile iron in cytosol, mitochondria and lysosomes. Metallomics 10:899-916. https://doi.org/10.1039/C8MT0 0048D

4. Kafina MD, Paw BH (2017) Intracellular iron and heme trafficking and metabolism in developing erythroblasts. Metallomics 9:1193-1203. https://doi.org/10.1039/c7mt00103g

5. Stehling O, Wilbrecht C, Lill R (2014) Mitochondrial iron-sulfur protein biogenesis and human disease. Biochimie 100:61-77. https://doi.org/10.1016/j.biochi.2014.01.010

6. Maio N, Rouault TA (2015) Iron-sulfur cluster biogenesis in mammalian cells: new insights into the molecular mechanisms of cluster delivery. Biochim Biophys Acta Mol Cell Res 1853:14931512. https://doi.org/10.1016/j.bbamcr.2014.09.009

7. Kimura S, Suzuki T (2015) Iron-sulfur proteins responsible for RNA modifications. Biochim Biophys Acta Mol Cell Res 1853:1272-1283. https://doi.org/10.1016/j.bbamcr.2014.12.010
8. Lopez CA, Skaar EP (2018) The impact of dietary transition metals on host-bacterial interactions. Cell Host Microbe 23:737-748. https://doi.org/10.1016/j.chom.2018.05.008

9. Pope M, Kalra PR (2018) Iron deficiency in heart failure: to treat or not to treat? Curr Treat Options Cardiovasc Med 20:65. https ://doi.org/10.1007/s11936-018-0661-8

10. Martins AC, Almeida JI, Lima IS et al (2017) Iron metabolism and the inflammatory response. IUBMB Life 69:442-450. https ://doi.org/10.1002/iub.1635

11. Lopez A, Cacoub P, Macdougall IC, Peyrin-Biroulet L (2016) Iron deficiency anaemia. Lancet 387:907-916. https://doi.org/10.1016/ S0140-6736(15)60865-0

12. Winterbourn CC (1995) Toxicity of iron and hydrogen peroxide: the Fenton reaction. Toxicol Lett 82-83:969-974

13. Dev S, Babitt JL (2017) Overview of iron metabolism in health and disease. Hemodial Int 21:S6-S20. https://doi.org/10.1111/ hdi. 12542

14. Manz DH, Blanchette NL, Paul BT et al (2016) Iron and cancer: recent insights. Ann N Y Acad Sci 1368:149-161. https://doi. org/10.1111/nyas. 13008

15. Apostolakis S, Kypraiou A-M (2017) Iron in neurodegenerative disorders: being in the wrong place at the wrong time? Rev Neurosci 28:893-911. https://doi.org/10.1515/revneuro-2017-0020

16. Belaidi AA, Bush AI (2016) Iron neurochemistry in Alzheimer's disease and Parkinson's disease: targets for therapeutics. J Neurochem 139:179-197. https://doi.org/10.1111/jnc.13425

17. Lertsuwan K, Wongdee K, Teerapornpuntakit J, Charoenphandhu $\mathrm{N}$ (2018) Intestinal calcium transport and its regulation in thalassemia: interaction between calcium and iron metabolism. J Physiol Sci 68:221-232. https://doi.org/10.1007/s12576-018-0600-1

18. Lane DJR, Merlot AM, Huang ML-H et al (2015) Cellular iron uptake, trafficking and metabolism: key molecules and mechanisms and their roles in disease. Biochim Biophys Acta Mol Cell Res 1853:1130-1144. https://doi.org/10.1016/j.bbamc r.2015.01.021

19. Pondarré C, Antiochos BB, Campagna DR et al (2006) The mitochondrial ATP-binding cassette transporter Abcb7 is essential in mice and participates in cytosolic iron-sulfur cluster biogenesis. Hum Mol Genet 15:953-964. https://doi.org/10.1093/hmg/ddl01 2

20. Bekri S, Kispal G, Lange H et al (2000) Human ABC7 transporter: gene structure and mutation causing X-linked sideroblastic anemia with ataxia with disruption of cytosolic iron-sulfur protein maturation. Blood 96:3256-3264

21. Raskind WH, Wijsman E, Pagon RA et al (1991) X-linked sideroblastic anemia and ataxia: linkage to phosphoglycerate kinase at Xq13. Am J Hum Genet 48:335-341

22. Shimada Y, Okuno S, Kawai A et al (1998) Cloning and chromosomal mapping of a novel ABC transporter gene (hABC7), a candidate for X-linked sideroblastic anemia with spinocerebellar ataxia. J Hum Genet 43:115-122. https://doi.org/10.1007/s1003 80050051

23. Csere P, Lill R, Kispal G (1998) Identification of a human mitochondrial $\mathrm{ABC}$ transporter, the functional orthologue of yeast Atm1p. FEBS Lett 441:266-270

24. Lunetti P, Damiano F, De Benedetto G et al (2016) Characterization of human and yeast mitochondrial glycine carriers with implications for heme biosynthesis and anemia. J Biol Chem 291:19746-19759. https://doi.org/10.1074/jbc.M116.736876

25. Krishnamurthy PC, Du G, Fukuda Y et al (2006) Identification of a mammalian mitochondrial porphyrin transporter. Nature 443:586-589. https://doi.org/10.1038/nature05125

26. Bayeva M, Khechaduri A, Wu R et al (2013) ATP-binding cassette B10 regulates early steps of heme synthesis. Circ Res 113:279287. https://doi.org/10.1161/CIRCRESAHA.113.301552 
27. Guernsey DL, Jiang H, Campagna DR et al (2009) Mutations in mitochondrial carrier family gene SLC25A38 cause nonsyndromic autosomal recessive congenital sideroblastic anemia. Nat Genet 41:651-653. https://doi.org/10.1038/ng.359

28. Yamamoto M, Arimura H, Fukushige T et al (2014) Abcb10 role in heme biosynthesis in vivo: Abcb10 knockout in mice causes anemia with protoporphyrin IX and iron accumulation. Mol Cell Biol 34:1077-1084. https://doi.org/10.1128/MCB.00865-13

29. Fleming MD, Campagna DR, Haslett JN et al (2001) A mutation in a mitochondrial transmembrane protein is responsible for the pleiotropic hematological and skeletal phenotype of flexedtail (f/f) mice. Genes Dev 15:652-657. https://doi.org/10.1101/ $\operatorname{gad} .873001$

30. Gregory CJ, McCulloch EA, Till JE (1975) The cellular basis for the defect in haemopoiesis in flexed-tailed mice. III. Restriction of the defect to erythropoietic progenitors capable of transient colony formation in vivo. Br J Haematol 30:401-410

31. Chui DH, Sweeney GD, Patterson M, Russell ES (1977) Hemoglobin synthesis in siderocytes of flexed-tailed mutant (f/f) fetal mice. Blood 50:165-177

32. Yoshikumi Y, Mashima H, Ueda N et al (2005) Roles of CTPL/ Sfxn3 and Sfxn family members in pancreatic islet. J Cell Biochem 95:1157-1168. https://doi.org/10.1002/jcb.20481

33. Amorim IS, Graham LC, Carter RN et al (2017) Sideroflexin 3 is an $\alpha$-synuclein-dependent mitochondrial protein that regulates synaptic morphology. J Cell Sci 130:325-331. https://doi. org/10.1242/jcs. 194241

34. Hildick-Smith GJ, Cooney JD, Garone C et al (2013) Macrocytic anemia and mitochondriopathy resulting from a defect in sideroflexin 4. Am J Hum Genet 93:906-914. https://doi.org/10.1016/j. ajhg.2013.09.011

35. Gylfe AE, Katainen R, Kondelin J et al (2013) Eleven candidate susceptibility genes for common familial colorectal cancer. PLoS Genet 9:e1003876. https://doi.org/10.1371/journal.pgen.1003876

36. Miotto G, Tessaro S, Rotta GA, Bonatto D (2007) In silico analyses of Fsf1 sequences, a new group of fungal proteins orthologous to the metazoan sideroblastic anemia-related sideroflexin family. Fungal Genet Biol 44:740-753. https://doi.org/10.1016/j. fgb.2006.12.004

37. Sanjana NE, Shalem O, Zhang F (2014) Improved vectors and genome-wide libraries for CRISPR screening. Nat Methods 11:783-784. https://doi.org/10.1038/nmeth.3047

38. Hirayama T, Kadota S, Niwa M, Nagasawa H (2018) A mitochondria-targeted fluorescent probe for selective detection of mitochondrial labile Fe(ii). Metallomics 10:794-801. https://doi. org/10.1039/c8mt00049b

39. Yuan X, Rietzschel N, Kwon H et al (2016) Regulation of intracellular heme trafficking revealed by subcellular reporters. Proc Natl Acad Sci 113:E5144-E5152. https://doi.org/10.1073/pnas.16098 65113

40. Alam MM, Lal S, FitzGerald KE, Zhang L (2016) A holistic view of cancer bioenergetics: mitochondrial function and respiration play fundamental roles in the development and progression of diverse tumors. Clin Transl Med 5:3. https://doi.org/10.1186/ s40169-016-0082-9

41. Wei F-Y, Zhou B, Suzuki T et al (2015) Cdk5rap1-mediated 2-methylthio modification of mitochondrial tRNAs governs protein translation and contributes to myopathy in mice and humans. Cell Metab 21:428-442. https://doi.org/10.1016/j. cmet.2015.01.019

42. Fakruddin M, Wei FY, Emura S et al (2017) Cdk5rap1-mediated 2-methylthio-N6-isopentenyladenosine modification is absent from nuclear-derived RNA species. Nucleic Acids Res 45:11954 11961. https://doi.org/10.1093/nar/gkx819

43. Paradkar PN, Zumbrennen KB, Paw BH et al (2009) Regulation of mitochondrial iron import through differential turnover of mitoferrin 1 and mitoferrin 2. Mol Cell Biol 29:1007-1016. https://doi. org/10.1128/MCB.01685-08

44. Puccio H, Simon D, Cossée M et al (2001) Mouse models for Friedreich ataxia exhibit cardiomyopathy, sensory nerve defect and $\mathrm{Fe}-\mathrm{S}$ enzyme deficiency followed by intramitochondrial iron deposits. Nat Genet 27:181-186. https://doi.org/10.1038/84818

45. Cotter PD, Rucknagel DL, Bishop DF (1994) X-linked sideroblastic anemia: identification of the mutation in the erythroid-specific delta-aminolevulinate synthase gene (ALAS2) in the original family described by Cooley. Blood 84:3915-3924

46. Dixon SJ, Lemberg KM, Lamprecht MR et al (2012) Ferroptosis: an iron-dependent form of nonapoptotic cell death. Cell 149:1060-1072. https://doi.org/10.1016/j.cell.2012.03.042

47. Ulrich DL, Lynch J, Wang Y et al (2012) ATP-dependent mitochondrial porphyrin importer ABCB6 protects against phenylhydrazine toxicity. J Biol Chem 287:12679-12690. https://doi. org/10.1074/jbc.M111.336180

48. Kory N, Wyant GA, Prakash G et al (2018) SFXN1 is a mitochondrial serine transporter required for one-carbon metabolism. Science 362(80-):eaat9528. https://doi.org/10.1126/science.aat95 28

49. Baron MH, Isern J, Fraser ST (2012) The embryonic origins of erythropoiesis in mammals. Blood 119:4828-4837. https://doi. org/10.1182/blood-2012-01-153486

50. Tracz MJ, Alam J, Nath KA (2007) Physiology and pathophysiology of heme: implications for kidney disease. J Am Soc Nephrol 18:414-420. https://doi.org/10.1681/ASN.2006080894

51. Chacinska A, Koehler CM, Milenkovic D et al (2009) Importing mitochondrial proteins: machineries and mechanisms. Cell 138:628-644. https://doi.org/10.1016/j.cell.2009.08.005

52. Otera $\mathrm{H}$, Taira $\mathrm{Y}$, Horie $\mathrm{C}$ et al (2007) A novel insertion pathway of mitochondrial outer membrane proteins with multiple transmembrane segments. J Cell Biol 179:1355-1363. https://doi. org/10.1083/jcb.200702143

53. Livak KJ, Schmittgen TD (2001) Analysis of relative gene expression data using real-time quantitative PCR and the $2^{\Delta \Delta \mathrm{C}_{t}}$ method. Methods 25:402-408

54. Fyrestam J, Östman C (2017) Determination of heme in microorganisms using HPLC-MS/MS and cobalt(III) protoporphyrin IX inhibition of heme acquisition in Escherichia coli. Anal Bioanal Chem 409:6999-7010. https://doi.org/10.1007/s0021 6-017-0610-5

Publisher's Note Springer Nature remains neutral with regard to jurisdictional claims in published maps and institutional affiliations 